\title{
EUS-guided Gastroenterostomy: Assessing the Competence of the Endoscopist
}

\author{
Anuraag Jena ${ }^{1} \quad$ Surinder Singh Rana ${ }^{1}$ \\ ${ }^{1}$ Department of Gastroenterology, Postgraduate Institute of \\ Medical Education and Research (PGIMER), Chandigarh, India
}

\begin{abstract}
Address for correspondence Surinder S. Rana, MD, DM, FASGE, Department of Gastroenterology, Postgraduate Institute of Medical Education and Research (PGIMER), Chandigarh 160012, India (e-mail: drsurinderrana@gmail.com).
\end{abstract}

\author{
Abstract \\ Keywords \\ - endosonography \\ - stomach \\ - gastric outlet \\ obstruction
}

Assessing competence is of utmost importance for complex EUS procedures like EUS-guided gastroenterostomy (EUS-GE) that are associated with higher risk of procedural complications. It is a matter of intense debate on what is the training needed to carry out these interventions, how to judge for competence, and who can perform these newer interventions. The procedure has several variations including the methods to identify the jejunal loops on EUS like direct puncture, balloon-assisted, and hybrid rendezvous with ultrathin endoscope. Therefore, there is lack of clarity on the role and ways of assessing the learning curve for EUS-GE. In this news and views, we are discussing two studies that assessed the learning curve for EUS-GE.
In absence of dedicated fellowship in advanced endoscopy procedures like endoscopic ultrasound (EUS) in our country, imparting adequate training in these procedures is a challenge. These advanced procedures can be either trained in a formal way like a structured fellowship in a dedicated tertiary training center for 6 to 24 months or informally via endoscopy workshops, which usually include short hands-on experiences. The hand-on experience can be either performed on models that are prepared using porcine organs or devoid of animal material or on live pigs or on simulators. ${ }^{1}$ However, these short-term learning modules have not been found to be cost-effective learning procedures. ${ }^{2}$ Therefore, many gastroenterologists are self-learning these procedures by watching online videos and attending live sessions of the endoscopy workshops. However, this self-learning of endoscopic procedures compromises the patient's safety, and learning in the absence of mentor is also suboptimal. Therefore, it is important to learn advanced endoscopic procedures under expert supervision till one reaches the plateau of the learning curve. Herein comes the concept of adequate competency and one way of assessing the same is to quantify the number of procedures that are needed to reach the plateau of learning curve.
Assessing competence is of utmost importance for complex endoscopic ultrasound (EUS) procedures like EUS-guided gastroenterostomy (EUS-GE) that are associated with a higher risk of procedural complications. ${ }^{3-5}$

Gastric outlet obstruction (GOO) can have benign or malignant causes. The mainstay of management in these patients is the relief of obstruction. In the past, surgery was the only modality for treatment of these patients. However, surgical gastro-jejunostomy has its own limitations, including prolonged hospital stay, and can only be offered to surgically fit patients. Advancement in endoscopic therapy has led to the development of luminal self-expanding metallic enteric stents. This, in turn, has led to minimally invasive approach for relieving GOO. Stent migration and occlusion are major limitations of luminal self-expanding metallic stents (SEMS), and therefore there are increased efforts to improve the results of endoscopic palliation. With the advent of EUS, newer treatment approaches are on horizon. Therapeutic EUS-guided interventions like drainage of pancreatic fluid collections, biliary and pancreatic duct drainage have revolutionized the results of endotherapy, especially when conventional endoscopic methods fail..$^{5-7}$ EUS-GE is a
DOI https://doi.org/ $10.1055 / \mathrm{s}-0040-1722361$ ISSN 0976-5042.
(C)2020. Society of Gastrointestinal Endoscopy of India.

This is an open access article published by Thieme under the terms of the Creative Commons Attribution-NonDerivative-NonCommercial-License, permitting copying and reproduction so long as the original work is given appropriate credit. Contents may not be used for commercial purposes, or adapted, remixed, transformed or built upon. (https://creativecommons.org/licenses/by-nc-nd/4.0/).

Thieme Medical and Scientific Publishers Pvt. Ltd. A-12, 2nd Floor, Sector 2, Noida-201301 UP, India 
new EUS-guided therapeutic procedure for the management of GOO.

The novel EUS-guided interventions are performed at few highly specialized tertiary care centers. It is a matter of intense debate on what is the training needed to carry out these interventions, how to judge for competence, and who can perform these newer interventions. Lack of guidelines for assessing competency as well as structured training curriculum for performing such interventions is a major drawback for widespread use of these complex interventions. Expertise on procedures will also reduce these complications, and therefore it is critical to perform initial procedures under expert supervision. This has led to the concept of a learning curve for assessing the competence of the endoscopist. It is based on the fact that with each new procedure, the time taken to perform the procedure is more than the ideal time needed, and gradually by doing more and more procedures, the time needed will start decreasing and reach a plateau, which would be close to the ideal time.

EUS-GE is a complex and tedious procedure, and development of cautery-enhanced lumen-apposing metallic fully covered stents (LAMS) (AXIOS stents [Boston Scientific, USA]) has improved the safety profile of this procedure. The procedure has several variations including the methods to identify the jejunal loops on EUS like direct puncture, balloon assisted, and hybrid rendezvous with ultrathin endoscope. Therefore, there is lack of clarity on the role and ways of assessing the learning curve for EUS-GE. ${ }^{8}$ There is currently no data on the number of EUS-GE procedures needed to be conducted in order to achieve competence. In this news and views, we are discussing two studies that have assessed the learning curve for EUS-GE.

Tyberg et al aimed to study the learning curve of EUS-GE in 23 patients with GOO (etiology was malignant in $48 \%$ patients) prospectively. ${ }^{9}$ The methods to identify the small bowel loop were intraluminal balloon in 57\%, hybrid rendezvous with ultraslim scope in $26 \%$, direct puncture in $13 \%$, and reverse entero-gastrostomy in the remaining $4 \%$ patients. They used cautery-enhanced LAMS in only seven patients. The technical success was $96 \%$ and the clinical success was $95 \%$. The median procedure time was 88 minutes (45-140 minutes). The periprocedural complication was seen in one patient (esophageal tear; repaired with clips), while minor post procedure complications were seen in five patients. The reintervention for stent revision or removal was done in four patients. The cumulative sum chart analysis showed that the procedure time of 88 minutes was achieved at the seventh procedure. They also reported that even after bridging the misdeployed LAMS, the procedure duration further reduced, with consequent procedures suggesting improvement with experience (nonlinear regression $p<0.0001$ ). Small sample size, varied techniques used for small bowel access, and electrocautery-enhanced LAMS being used in a small number of patients were important limitations of study. The authors concluded that endoscopists achieve a reduction in procedure time over successive cases, with a learning rate of seven cases.
Jovani et al published a retrospectively analyzed study of 87 consecutive GOO patients (malignant etiology-88\%) who underwent EUS-GE in a tertiary care center in the USA from 2014-2020. ${ }^{10}$ They excluded three patients for altered surgical anatomy and 11 patients for noncautery-enhanced procedures to maintain homogeneity. They used freehand cautery-enhanced intervention for the rest of the 73 patients. They injected $500 \mathrm{~mL}$ of saline, methylene blue and contrast with the help of forward view endoscope. Later, under EUS guidance, 19G EUS needle was used to aspirate blue-tinged fluid to confirm position in jejunum. This was followed by free hand deployment of LAMS. The technical success was seen in 93\% patients, while clinical success was seen in $97 \%$ cases. The mean duration of the procedure was $36 \pm 24$ minutes. Immediate adverse events were observed in four patients during the initial 39 cases (misdeployment-3, conservatively managed hemoperitoneum-1). Late adverse event was seen in only one patient (stent migration). The authors, on cumulative sum analysis, found that experience of 25 cases was needed to attain proficiency and 40 cases for mastery. The mean procedural time for patients 25 to 39 and for patients 40 to 73 were significantly lower compared with the first 24 procedures. Retrospective nature of study, small sample size, and lack of standard technique were important limitations of this study.

\section{Commentary}

The learning curve is a good way to judge competency in any surgical or minimally invasive procedures like EUS-guided innovative procedures. It is a graphical representation of the relationship between the learning effort and outcome. ${ }^{10}$ There should be two milestones for budding gastroenterology fellows in any endoscopic intervention-proficiency and mastery. With new interventions, the learning curve should always be determined, so as to minimize complications and have widespread acceptance of the new technique. EUS-GE is an attractive option for patients in whom surgery is contraindicated. However, there is no standardized technique for EUS-GE. It is difficult to compare the mean time of procedure when the methods used to access a small bowel loop are different. The expertise of the endoscopist also determines the procedure time and technical success. Moreover, there is no structured training in advanced EUS, with no agreed methods of assessing the competency. The above-discussed studies have reported on the learning curve for EUS-GE at centers with extensive experience in diagnostic and interventional EUS at a tertiary referral center. With improving and changing medical education and training, more emphasis is being placed on competency-based evaluation and promotion, which includes the assessment of important quality indicators. It is also important to remember that the outcome measures are also determined by the technological and procedural changes, and therefore the number of procedures required to achieve competence as well as the procedural time are going to decrease with advancement in technology and accessories. ${ }^{11}$ 
To conclude, the learning curve is a vital component for all interventions. It is high time they should be incorporated in all the guidelines and be put to use for the welfare of patients. As of now, there is no such guidance for the learning curve of EUS-GE. The future lies in creating a curriculum for trainees, based on the learning curves, so as to ensure performance of complex endoscopic procedures independently with better outcomes and negligible adverse effects.

Conflict of Interest

None declared.

\section{References}

1 Gonzalez JM, Cohen J, Gromski MA, Saito K, Loundou A, Matthes $\mathrm{K}$. Learning curve for endoscopic ultrasound-guided fine-needle aspiration (EUS-FNA) of pancreatic lesions in a novel ex-vivo simulation model. Endosc Int Open 2016;4(12):E1286-E1291

2 Kim GH, Bang SJ, Hwang JH. Learning models for endoscopic ultrasonography in gastrointestinal endoscopy. World J Gastroenterol 2015;21(17):5176-5182

3 Wani S, Coté GA, Keswani R, et al. Learning curves for EUS by using cumulative sum analysis: implications for American Society for Gastrointestinal Endoscopy recommendations for training. Gastrointest Endosc 2013;77(4):558-565

4 Sharma V, Rana SS, Bhasin DK. Endoscopic ultrasound guided interventional procedures. World J Gastrointest Endosc 2015;7(6):628-642
5 Rana SS, Shah J, Kang M, Gupta R. Complications of endoscopic ultrasound-guided transmural drainage of pancreatic fluid collections and their management. Ann Gastroenterol 2019;32(5):441-450

6 Rana SS, Sharma R, Gupta R. EUS-guided transmural pancreatic duct interventions for relief of pain in patients with chronic pancreatitis and failed ERCP. Endosc Ultrasound 2020; 9(4):274-275

7 Dalsania R, Shah R, Rana S, Chawla S. Endoscopic ultrasoundguided management of chronic pancreatitis. Curr Gastroenterol Rep 2020;22(7):34

8 Khashab MA, Bukhari M, Baron TH, et al. International multicenter comparative trial of endoscopic ultrasonography-guided gastroenterostomy versus surgical gastrojejunostomy for the treatment of malignant gastric outlet obstruction. Endosc Int Open 2017;5(4):E275-E281

9 Tyberg A, Kats D, Choi A, Gaidhane M, Nieto J, Kahaleh M. Endoscopic ultrasound guided gastroenterostomy: what is the learning curve? J Clin Gastroenterol 2020; early online

10 Jovani M, Ichkhanian Y, Parsa N, Singh S, Brewer Gutierrez OI, Keane MG, Al Ghamdi SS, Ngamruengphong S, Kumbhari V, Khashab MA. Assessment of the learning curve for EUS-guided gastroenterostomy for a single operator. Gastrointest Endosc. 2020 Sep 28: doi: 10.1016/j.gie.2020.09.041

11 Valsamis EM, Chouari T, O'Dowd-Booth C, Rogers B, Ricketts D. Learning curves in surgery: variables, analysis and applications. Postgrad Med J 2018;94(1115):525-530 